\title{
Case Study of a Giant Cell Tumour of a Tendon Sheath
}

\author{
Dr Rajesh Ambulgekar ${ }^{1}$, Dr Prajyot Kandolkar², Dr Rohit Thakkar ${ }^{3}$, \\ Dr Rahul Berlia ${ }^{4}$ \\ Department of Orthopaedic , Dr Shankar-rao Chavan Government Medical College, Nanded, Maharashtra
}

\begin{abstract}
Giant cell tumour of tendon sheath of tendo-achilies is not a common tumour, it has high rate of recurrence. In this article we present one such tumour treated by is excision with no recurrence after 6 months of follow up.
\end{abstract}

Keywords: Giant cell tumour, Tendoachilies, excision

\section{Introduction}

Giant cell tumour of tendon sheath is an uncommon tumour. Commonly it arises from the tendon of muscles of hand and foot; less common are elbow and ankle. It arises from synovial membrane of large joints like knee, elbow. It has high rate of recurrence. If tumour is excised properly the risk of recurrence is much lower.

\section{Case Report}

35 year old male presented to outpatient department of our hospital with swelling of right ankle for 3 months. Swelling was painless to start with gradually kept increasing in size and reached the size of golf ball. Patient had dull aching pain at the time of presentation. However there was no limping while walking. No history of fever or trauma.

On examination swelling was firm, cystic, non-tender, had lobulated and well defined margins. Overlying skin was free from swelling. It was moving with Achilles tendon but not along the tendon .On active planter flexion tumour was fixed to tendon. Transillumination test was performed and was however negative, however fluctuation was positive. There was no weight loss.

$\mathrm{X}$ ray was done of ankle, which showed no pathology, FNAC was done which showed giant cell tumour with spindle cells.

Biopsy of tumour was done again which showed giant cell tumour with spindle cells. There was no evidence of malignancy on histopathological examination.

Diagnosis of Giant cell tumour of tendon sheath was made. Giant cell tumour was excised from achilies tendon with its capsule and sent for histopathological examination. Histopathology conformed diagnosis. Intraoperatively, tumour was lobulated, firm, capsulated, cystic, and red-brown in colour. Wound healed well and sutures were removed on tenth postoperative day. Patient was able to walk well without any discomfort and was followed regularly every month for 6 months. Till today no recurrence has been seen.

\section{Discussion}

Giant cell tumour of tendon sheath is an uncommon tumour. It's a benign tumour. Male and female both are affected equally. $[1,9,6]$ Tumour mostly arises from tendons flexors of fingers and hand followed by toes, then commonly from tendons of face and tendon around elbow and ankle. Tumour can also arise from joints like knee, ankle, and elbow. [2, 9, 6, 7]

Mostly tumour is benign and arises from synovial membrane. Tumour is painless, non-tender, slow growing. [1, 9] It has well distinct lobulated margins. Tumour has a firm consistency. Plantar flexion is positive but Trans illumination is negative. This differentiates this tumour from ganglion. [1, 2, 6, 9]

Tumour is divided into two types i.e. local and diffuse. Local is mostly common and benign and arises from tendon sheath of fingers of hand. Diffuse tumour arises from intra-articular site. It resembles pigmented villo-nodular synuvitis. Hence it is classified as pigmented vilo-nodular synovitis. It is more aggressive and chances of recurrence are high. [1, 3, 67$]$

Al quatan devised a classification system for Giant cell tumour of tendon sheath to prognosticate lesions with high chances of recurrence. Tumours were divided into two depending upon whether entire tumour was surrounded by pseudo capsule(Type 1) or not(Type 2), and further subdivided into single, multilobulated and multicentric nodule.[1, 2]

Microscopically it consists of multinodular giant cell inter-spared in background of polygonal ovoid mononuclear cells. Patches of hyalinised tissue, collagenous fibres xanthomatous foci composed of lipid laden monophages or foam cells are seen with rare or absent cellular or mitotic figure. [1, 3, 4]It has high risk of 
recurrence. Reported rate of recurrence is 9-44\% [1]Single tumour cells or multiloculated and type ii $2^{\text {nd }}$ more distent tumour. Etiology not known may be traumatic and neoplastic or inflammatory following chronic antigenic stimulation. [8]Absence of gene nn23 is associated with high recurrence rate. [1] Expression of CD 68 marker by tumour cells suggests that the tumour cells are arising from histiocytes. [5]Differential diagnosis is epithelia sarcoma, malignant fibroma, hisitocytoma, neurofibroma or dermofibroma etc. [8] MRI both T1 and T2 weighing image shows low signal intensity. [8] Drug of choice for treatment of tumour is imatinib mesyplate.

\section{Conclusion}

Giant cell tumor of the tendon sheath is a rare, benign tumour of hand. Nevertheless, giant cell tumour of the tendon sheath should not be eliminated from the index of suspicion in nodular swellings of the hand. The basic aim of management should be early diagnosis with operative excision. [4]

\section{References}

[1]. giant cell tumour of tendon sheath: case series and reviewOf literatures. s. Suresh \& hosam zaki

[2]. giant cell tumour of the tendon sheath in theknee of an 11-year-old girlarifaizad abdullah, shalimar abdullah*, nor hazla mohd haflah, sharaf Ibrahim department of orthopaedics, faculty of medicine, university kebangsaan malaysia, kuala lumpur, malaysia.

[3]. giant-cell tumour of the tendon sheath is radiotherapy indicated to prevent recurrence after surgery? prakash p. kotwal, vikas gupta, rajesh malhotra from the all india institute of medical sciences, new delhi, india

[4]. giant cell tumor of the flexor tendon sheath of the hand mazheruddin ali khan and mohammed mateen department of orthopedics, owaisi hospital and research centre, deccan college of medical sciences, hyderabad 500 058, andhra pradesh, india. case reportgiant cell tumor of the tendon sheath composed largely ofepithelioid histiocytes tadashi teradadepartments of pathology, shizuoka city shimizu hospital, shizuoka, japan

[5]. case report giant cell tumor of the tendon sheath composed largely of epithelioid histiocytes tadashi terada departments of pathology, shizuoka city shimizu hospital, shizuoka, japan

[6]. giant cell tumor of tendon sheath in the foot: case studies annette d. filiatrault, dpmjoe t. southerland, dpm william d. fishco, dpm

[7]. multifocal giant cell tumor of the tendon sheath occuring at different localizations of the same tendon of a finger:a case report and review of the literature aslı altaykan, m.d.,1 kemalettin yıldız, m.d.,2 onur hapa, m.d.,3 selma çukur, m.d.4departments of 1dermatology, 2plastic and reconstructive surgery, 3orthopaedics and traumatology, and 4pathology, bolu zzetbaysal State hospital, bolu, turkey

[8]. chapter 21: benign/aggressive tumors of bone," in campbell's operative orthopaedics, t. s. canale, ed., vol. 1, pp. 883-886,mosby, new york, ny, usa, 11th edition, 2007.
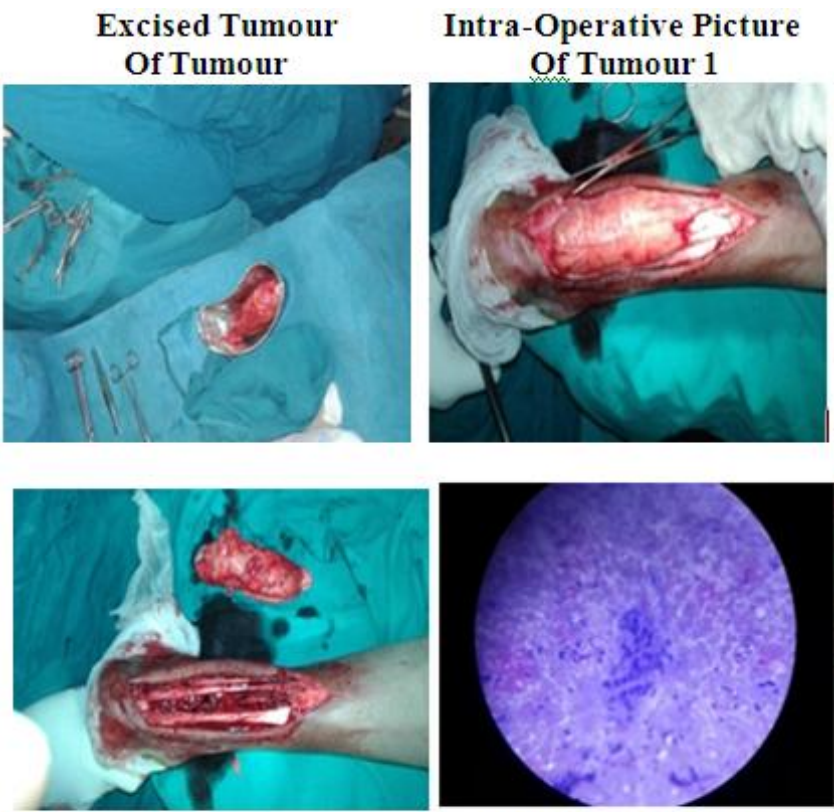

Intraoperative Picture Of Tumour 3

\section{Intra-Operative Picture} Of Tumour 1

Intraoperative Picture Of Tumour 2
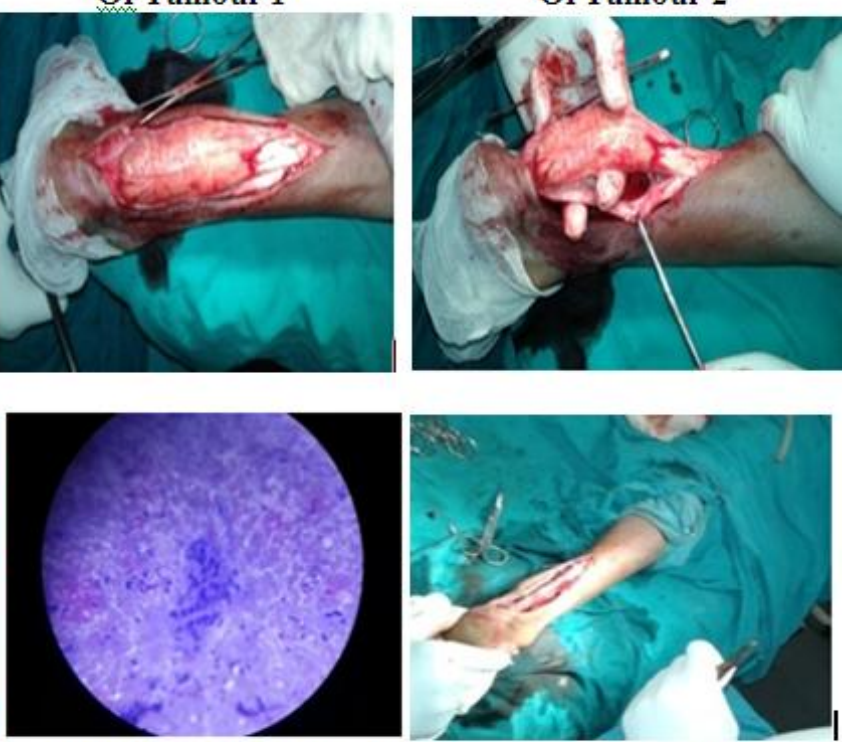

Microscopic Picture 1

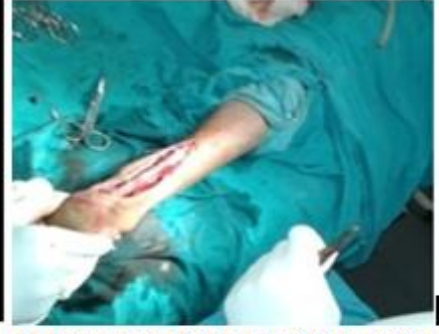

Intraoperative Picture After Excission 1 
Post Operative Scar 1

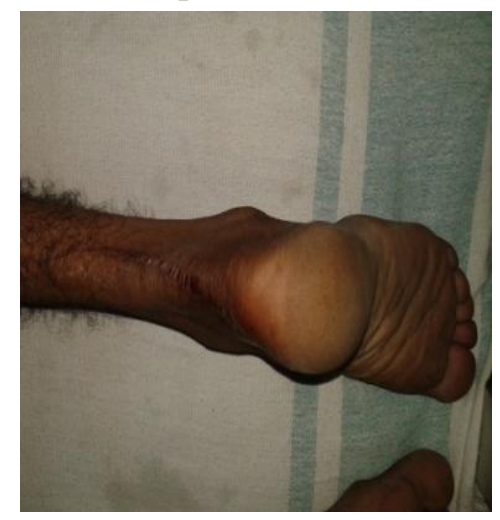

6 Months Follow Up 1

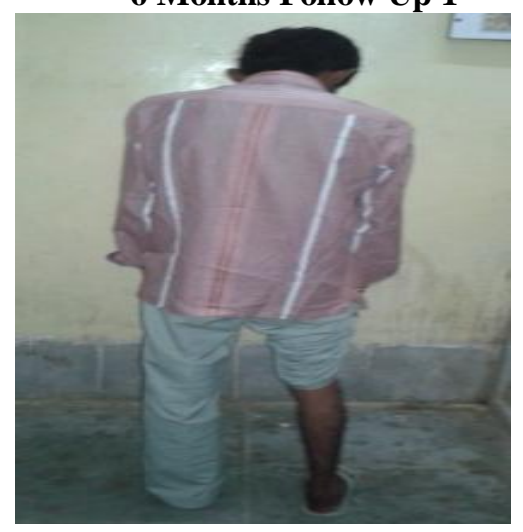

